\title{
Positively Charged Amino Acids at the SNAP-25 C Terminus Determine Fusion Rates, Fusion Pore Properties, and Energetics of Tight SNARE Complex Zippering
}

\author{
QQ Qinghua Fang, ${ }^{1,2}$ Ying Zhao, ${ }^{1,2}$ Adam Drew Herbst, ${ }^{1}$ Brian N. Kim, ${ }^{1}$ and Manfred Lindau ${ }^{1,2}$ \\ ${ }^{1}$ School of Applied and Engineering Physics, Cornell University, Ithaca, New York 14853, and ${ }^{2}$ Laboratory for Nanoscale Cell Biology, Max-Planck-Institute \\ for Biophysical Chemistry, D-37077 Göttingen, Germany
}

\begin{abstract}
SNAP-25 is a Q-SNARE protein mediating exocytosis of neurosecretory vesicles including chromaffin granules. Previous results with a SNAP-25 construct lacking the nine C terminal residues (SNAP-25 $\Delta$ 9) showed changed fusion pore properties (Fang et al., 2008), suggesting a model for fusion pore mechanics that couple $\mathrm{C}$ terminal zipping of the SNARE complex to the opening of the fusion pore. The deleted fragment contains the positively charged residues R198 and K201, adjacent to layers 7 and 8 of the SNARE complex. To determine how fusion pore conductance and dynamics depend on these residues, single exocytotic events in bovine chromaffin cells expressing $\mathrm{R} 198$ Q, R198E, K201Q, or K201E mutants were investigated by carbon fiber amperometry and cell-attached patch capacitance measurements. Coarse grain molecular dynamics simulations revealed spontaneous transitions between a loose and tightly zippered state at the SNARE complex C terminus. The SNAP-25 K201Q mutant showed no changes compared with SNAP-25 wild-type. However, K201E, $\mathrm{R} 198 \mathrm{Q}$, and R198E displayed reduced release frequencies, slower release kinetics, and prolonged fusion pore duration that were correlated with reduced probability to engage in the tightly zippered state. The results show that the positively charged amino acids at the SNAP-25 C terminus promote tight SNARE complex zippering and are required for high release frequency and rapid release in individual fusion events.
\end{abstract}

Key words: amperometry; capacitance; chromaffin cells; exocytosis; fusion pore; SNAP-25

\section{Introduction}

Many types of cells release specific molecules stored in intracellular vesicles by exocytosis via the formation of a fusion pore. The fusion pore connects the intravesicular lumen to the extracellular space, allowing for release of vesicular contents (Breckenridge and Almers, 1987). Fusion pore opening and fusion pore expansion are triggered by an increase in intracellular free calcium ions sensed by synaptotagmin (Fernández-Chacón et al., 2001; Sørensen et al., 2003a; Wang et al., 2006). This stimulus is thought to enable zippering of the SNARE (soluble $N$-ethylmaleimidesensitive factor attachment protein receptor) complex in a vectorial manner from the $\mathrm{N}$ terminus toward the $\mathrm{C}$ terminus (Sørensen, 2009) through a mechanism that involves the protein

Received July 16, 2014; revised Dec. 19, 2014; accepted Dec. 23, 2014.

Author contributions: Q.F., Y.Z., and M.L. designed research; Q.F. and Y.Z. performed research; A.D.H. and B.N.K. contributed unpublished reagents/analytic tools; Q.F., Y.Z., and B.N.K. analyzed data; Q.F., Y.Z., and M.L. wrote the paper.

This work was supported by the National Institutes of Health (Grants GM085808 and T32GM008267), the European Research Council (Grant ADG 322699), and the National Science Foundation (Agreement DGE-0654112 from the IGERT program). We thank Owasco Meat Company in Moravia, New York, for providing bovine adrenal glands, Joan Lenz for excellent technical assistance, and Oliver Beckstein for critically reading the manuscript.

The authors declare no competing financial interests.

Correspondence should be addressed to Dr. Manfred Lindau, Laboratory for Nanoscale Cell Biology, Max-PlanckInstitute for Biophysical Chemistry, D-37077 Göttingen, Germany. E-mail: mlindau@mpibpc.mpg.de or ml95@cornell.edu.

DOI:10.1523/JNEUROSCI.2905-14.2015

Copyright $\odot 2015$ the authors $\quad 0270-6474 / 15 / 353230-10 \$ 15.00 / 0$ complexin (Tang et al., 2006; Li et al., 2011). C terminal zippering of the SNARE complex provides the force and free energy to conquer the barriers for fusion (Gao et al., 2012) under the control of complexin (Maximov et al., 2009).

Fusion pore properties depend on multiple factors, including vesicle size (Klyachko and Jackson, 2002; Flašker et al., 2013), electrostatic interactions (Han and Jackson, 2005; Calejo et al., 2012), and the energetics of SNARE complex zippering. Botulinum toxin A cleaves off the $9 \mathrm{C}$ terminal residues of SNAP-25 and impairs release (Xu et al., 1998). Expression of SNAP-25 $\Delta 9$ (lacking the nine $\mathrm{C}$ terminus residues) in chromaffin cells leads to lower vesicle fusion frequency, smaller amperometric "footcurrent" amplitudes, reduced fusion pore conductance, and slower fusion pore expansion (Fang et al., 2008). Within this domain, mutations of the hydrophobic layer +8 residues of SNAP-25 (M202 or L81) or Synaptobrevin 2 (Syb2, also named VAMP2) (L84) slow down the rapid phase of exocytosis in chromaffin cells stimulated by a step increase of the intracellular free calcium concentration (Sørensen et al., 2006; Walter et al., 2010). However, electrostatic interactions also contribute to the $\mathrm{C}$ terminal interactions, as indicated by a reduction in the rate of fusion events and slower release kinetics from individual vesicles by the SNAP-25 K201E mutation (Gil et al., 2002). The 9 aa C terminal fragment of SNAP-25 contains two charged amino acids, R198 and K201. To study the role of these residues in fusion pore formation and expansion, SNAP-25 R198Q, R198E, K201Q, and 
K201E mutants were expressed in bovine chromaffin cells. Single exocytotic events were characterized experimentally by measurements of amperometric foot currents and cell-attached patch capacitance measurements. Changes in the energetics of $\mathrm{C}$ terminal SNARE complex interactions between Syb2 and Syntaxin 1A (Stx1A) produced by such mutations were analyzed by coarse grain molecular dynamics simulations of a SNARE complex fragment containing the four SNARE domains of the SNARE complex, as well as SNARE-transmembrane domain linker regions of Syb2 and Stx1A.

Our results show that both positively charged amino acids, R198 and K201, contribute to the ability of the SNARE complex to acquire a tightly zippered conformation at the $\mathrm{C}$ terminus and are required to optimize release frequency, but only mutations of R198 produced a different fusion pore conductance.

\section{Materials and Methods}

Cells and viral expression. Bovine chromaffin cells were prepared as described previously (Parsons et al., 1995). The large vesicle size ( 2-3 fF) and long fusion pore duration $(\sim 10 \mathrm{~ms})$ of bovine chromaffin cells are good for precise detection of fusion pore properties. Cells were incubated at $37^{\circ} \mathrm{C}, 8 \% \mathrm{CO}_{2}$, infected at day 1 after isolation, and used $24-36 \mathrm{~h}$ after infection. Virus production and infection were performed as described previously (Ashery et al., 1999). SNAP-25 mutant constructs were generated using the QuikChange Site-Directed Mutagenesis Kit (Stratagene) and verified by DNA sequence. The SNAP-25 wild-type (wt) and mutants were cloned into a modified pSFV1 (Semliki Forest virus vector) plasmid in which an internal ribosome entry site was inserted, followed by the gene for enhanced GFP, as described previously (Sørensen et al., 2002).

Capacitance measurement. Cell-attached patch-clamp capacitance measurements were performed with wide-tipped patch pipettes (tip diameter $\sim 5 \mu \mathrm{m}$ ) using an EPC-7 amplifier (HEKA) and a lock-in amplifier (SR830; Stanford Research Systems) applying a $20 \mathrm{kHz}, 50 \mathrm{mV}$ (root-mean square) sine wave. Data were recorded at $2 \mathrm{kHz}$ sampling rate and each cell was patched only once. Analysis of fusion pore conductance was performed as described previously (Debus and Lindau, 2000) and restricted to fusion pores with lifetimes $>4.5 \mathrm{~ms}$ because shorter events were distorted by the lock-in amplifier low-pass filter (set to 300 $\mu \mathrm{s}, 24 \mathrm{~dB}$ ). The bath and pipette solution were prepared as described previously (Fang et al., 2008).

Amperometry. Amperometry was performed using custom made 5 - $\mu \mathrm{m}$-diameter carbon fiber electrodes using a method based on Mundroff and Wightman (2002). Amperometric currents were recorded at 5 $\mathrm{kHz}$ sampling rate with an EPC-7 amplifier (HEKA) applying an electrode voltage of $+700 \mathrm{mV}$, filtered at $3 \mathrm{kHz}$, and analyzed by a customized macro for IGOR (Wavemetrics) software (Mosharov and Sulzer, 2005). The analysis was restricted to events with a peak amplitude $>10$ pA. For foot-signal analysis, the amperometric currents were subsequently filtered with a $500 \mathrm{~Hz}$ digital Bessel filter (IGOR IFDL) and analysis was restricted to events with foot amplitude $>0.5 \mathrm{pA}$ and foot duration $>2 \mathrm{~ms}$. The foot amplitude of an individual event was defined as the mean foot current during the foot duration (Mosharov and Sulzer, 2005). The bath solution and high $\mathrm{KCl}$ stimulation solution were prepared as described previously (Fang et al., 2008).

Molecular dynamics simulations. Coarse grain models of the SNARE complex components (Syb2 25-93, stx1A 188-259, SNAP-25 7-83, and SNAP-25 131-206) were generated from the crystal structure (Sutton et al., 1998) (pdb file 1SFC) after addition of S205 and G206 at the C terminus of SNAP-25 as helical extension using PyMOL (DeLano, 2002). The SNAP25 R198 and K201 mutants were also generated with PyMOL. Atomistic structures were converted to MARTINI force field coarse grained representations (Monticelli et al., 2008) and solvated, followed by steepest descend energy minimization. Molecular dynamics simulations were performed using GROMACS 4.5.4 (Van Der Spoel et al., 2005). For each system, eight simulations of 200 ns length were performed with random starting velocities. The system temperature, pres- sure, and coupling time constant were set to $310 \mathrm{~K}, 1 \mathrm{bar}$, and $0.1 \mathrm{ps}$, respectively. Individual trajectories were analyzed using a tcl script in VMD (Humphrey et al., 1996) generating trajectories for the distance (d) between the backbone particle of Syb2 Leu 84 (Layer 8) and that of Stx1A Ala 254 (Layer 8). Histograms of the distance values were converted to free energy $(\Delta G)$ diagrams, inverting the relation $n(d)=n_{0} \times \exp (-\Delta G /$ $\left.k_{\mathrm{B}} T\right)$, where $n(d)$ are the frequencies with which distances occur during the simulations.

Immunocytochemistry of SNAP-25. To quantify the SNAP-25 expression levels, bovine chromaffin cells and cells expressing SNAP-25 wt, R198Q, R198E, K201Q, or K201E mutants were cultured in glass-bottom dishes. $24 \mathrm{~h}$ after transfection, cell were fixed in $4 \%$ paraformaldehyde solution for $30 \mathrm{~min}$, permeabilized in $0.1 \%$ (v/v) Triton X-100 for 10 min, and blocked with $6 \%$ bovine albumin serum (Sigma-Aldrich) for $1 \mathrm{~h}$. After removing the blocking buffer, the cells were incubated with the primary mouse anit-SNAP-25 antibody (1:2000, CI 71.2, SYSY) for $2 \mathrm{~h}$, washed 5 times 10 min with PBS, incubated with Alexa Fluor 546-labeled secondary antibodies (Invitrogen, 1:200 dilutions) for $1 \mathrm{~h}$, washed, and mounted. Fluorescence imaging was performed with an inverted microscope (Zeiss Axiovert 135 TV with Plan-Neofluar $40 \times 0.75$ objective) equipped with $546 / 10 \times$ excitation filter, $600 \mathrm{~nm}$ dichroic, and a $600 \mathrm{~nm}$ long-pass emission filter. Images were acquired with an iXon EMCCD camera (Andor Technology) and analyzed using ImageJ.

Fura-red calcium imaging. A coverslip with adherent chromaffin cells was placed in a Petri dish with buffer containing $3 \mu \mathrm{M}$ cell permeable Fura-red AM (Life Technologies) for $10 \mathrm{~min}$ at room temperature. The coverslip was then transferred to a dish with a coverslip bottom, washed twice with buffer solution to remove the free dye, and mounted on a custom built stage in an inverted microscope (Zeiss Axiovert $135 \mathrm{TV}$ with Plan-Neofluar $40 \times 0.75$ objective) equipped with a $600 \mathrm{~nm}$ dichroic and a $600 \mathrm{~nm}$ long-pass emission filter. The fluorescence intensity was recorded at a rate of $0.34 \mathrm{~Hz}$ for a total recording time of $68 \mathrm{~s}$ using the iXon EMCCD camera. At each time point, a pair of images was acquired, using a filter wheel (Lambda 10-2; Sutter Instruments), switching between $436 / 10$ and 500/20 nm excitation filters. For stimulation, a glass pipette with $\sim 2.5 \mu \mathrm{m}$ tip diameter containing $100 \mathrm{mM} \mathrm{KCl}$ solution was positioned $\sim 40 \mu \mathrm{m}$ away from the cell and a $35 \mathrm{~s}, 4$ PSI $\left(\sim 2.8 \times 10^{4} \mathrm{~Pa}\right)$ puff was applied to the pipette using a pressure application system (PicoSpritzer II; Parker-Hannifin/General Valve).

Images were stored in 16-bit integer format and were analyzed using ImageJ. The background fluorescence intensity was determined for each image at each wavelength by taking the average of the intensity measured in a $\sim 25 \times 25 \mu \mathrm{m}^{2}$ square region in an area that did not include any cell or particles. This background value was subtracted from the average fluorescence intensity in a $\sim 25 \times 25 \mu \mathrm{m}^{2}$ square region surrounding each cell and the ratio of the $\mathrm{Ca}^{2+}$-sensitive $(500 \mathrm{~nm})$ over the $\mathrm{Ca}^{2+}$-insensitive $(436 \mathrm{~nm}$ ) channel determined. For each time point, the ratio from six to eight cells within a group was averaged. The data are presented as mean \pm SEM.

Statistical analysis. For each analyzed parameter, the median value was determined for each cell and the mean of these values was calculated. One-way ANOVA was applied to test statistical significance between groups of cells, with $n$ being the number of cells in a group.

\section{Results}

Transmitter release kinetics determined by amperometry

To investigate the role of positively charged amino acids in the $\mathrm{C}$ terminal domain of SNAP-25, SNAP-25 wt and R198Q, R198E, $\mathrm{K} 201 \mathrm{Q}$, or K201E mutants were overexpressed in bovine chromaffin cells (Fig. 1A). The expression levels of the SNAP-25 mutants and SNAP-25 wt were similar (Fig. $1 A, B$ ) and $\sim 7$-fold higher than the endogenous SNAP-25 expression level. Exocytosis was stimulated by $100 \mathrm{~mm} \mathrm{KCl}$ inducing depolarization. When one of the positively charged amino acids was replaced by negatively charged glutamate, the frequency of release events (Fig. $1 C, D)$ was reduced by $\sim 50 \%$ [SNAP-25 R198E $(11.03 \pm 2.25$ events/min), K201E(13.56 \pm 3.63 events/min)] compared with SNAP-25 wt $(28.25 \pm 3.22$ events/min $)$. The neutral amino 
acid mutant SNAP-25 R198Q (19.85 土 2.24 events/min) had $\sim 30 \%$ lower release frequency, whereas cells expressing SNAP-25 K201Q (28.83 \pm 3.29 events/ $\mathrm{min})$ had a similar release frequency as cells expressing SNAP-25 wt (Fig. 1C, D). The free intracellular $\mathrm{Ca}^{2+}$ concentration $\left(\left[\mathrm{Ca}^{2+}\right]_{\mathrm{i}}\right)$ is the key factor determining the rate of exocytotic fusion events. To exclude the possibility that the reduction in fusion rate was due to a change in $\left[\mathrm{Ca}^{2+}\right]_{\mathrm{i}}$ dynamics (Wiser et al., 1996; Condliffe et al., 2010), $\left[\mathrm{Ca}^{2+}\right]_{\mathrm{i}}$ was measured using Fura-red, which is suitable for use in GFPexpressing cells (Fig. 2A,B). The fluorescence intensity ratios at 500/436 nm excitation wavelength determined before and after $\mathrm{KCl}$ stimulation (Fig. 2C) and the time courses of the ratio change (Fig. 2D) were similar between control cells and cells overexpressing SNAP-25 or SNAP-25 R198E. These results show that the charged amino acids at the SNAP-25 C terminus do not affect $\left[\mathrm{Ca}^{2+}\right]_{\mathrm{i}}$ at rest or the $\left[\mathrm{Ca}^{2+}\right]_{\mathrm{i}}$ change in response to stimulation.

To determine whether the positively charged amino acids at the SNAP-25 C terminus also modulate release kinetics from individual vesicles, five parameters (Fig. 3A)_-quantal size, spike half-width, peak amplitude, foot duration, and foot amplitude-were determined for each amperometric spike. As shown in Figure $3 B$, events from SNAP-25 K201 and R198 mutants had a quantal size (R198Q, $1.26 \pm 0.19 \mathrm{pC}$; R198E, $1.20 \pm 0.09 \mathrm{pC}$; $\mathrm{K} 201 \mathrm{Q}, 1.23 \pm 0.24 \mathrm{pC}$; K201E, $1.20 \pm$ $0.18 \mathrm{pC}$ ) similar to that from SNAP-25 wt $(1.07 \pm 0.17 \mathrm{pC})$. However, except for the K201Q mutant $(12.3 \pm 1.0 \mathrm{~ms})$, the amperometric spike half-width (Fig. 3C) was significantly increased for K201E (19.4 \pm $2.1 \mathrm{~ms}), \mathrm{R} 198 \mathrm{Q}(18.6 \pm 1.5 \mathrm{~ms})$, and R198E mutants (22.6 $\pm 1.7 \mathrm{~ms})$ compared with that of SNAP-25 wt (10.2 $\pm 1.5 \mathrm{~ms})$. Consistent with the larger half-width, events from SNAP-25 R198Q (44.3 \pm 6.0 pA), R198E (36.8 $\pm 1.9 \mathrm{pA})$, and K201E $(48.0 \pm 4.4 \mathrm{pA})$ mutants have a smaller peak amplitude than those from SNAP-25 wt (67.2 $\pm 8.3 \mathrm{pA})$ and the K201Q (57.5 \pm 6.9 pA) mutant (Fig. 3D). Larger halfwidth and smaller peak amplitude of amperometric spike observed with SNAP-25 R198Q, R198E, and K201E mutants indicated that the transmitter release process from individual vesicles was slower than with SNAP-25 wt.

Amperometric spikes from chromaffin cells are frequently preceded by a foot signal (Chow et al., 1992), which reflects transmitter leakage during the early nar-
A
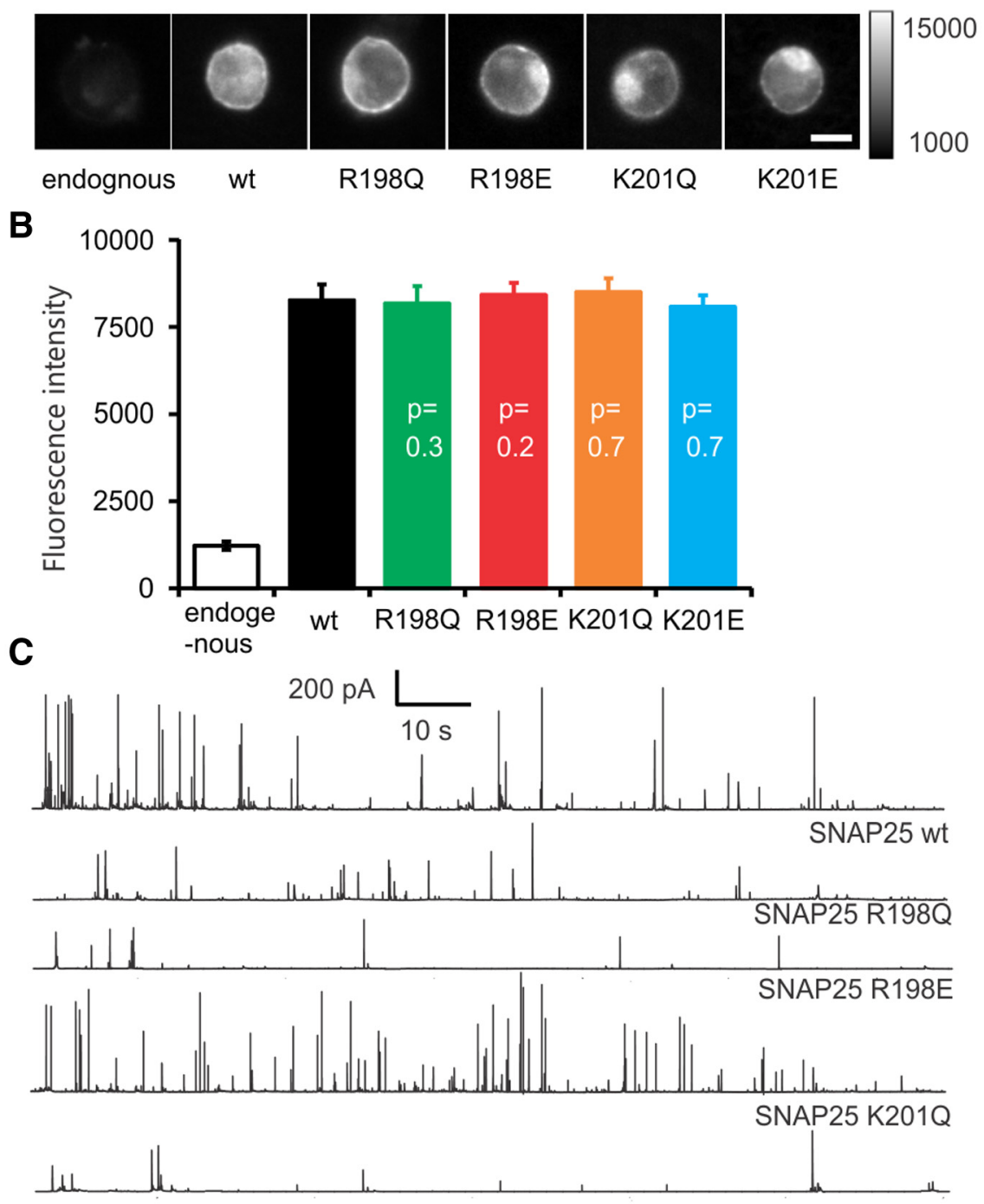

SNAP25 K201E

D

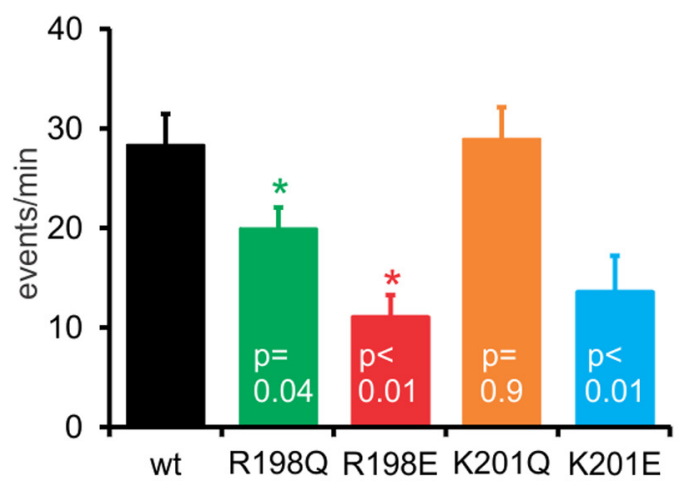

Figure 1. Positively charged amino acids at SNAP-25 C terminus are required for high transmitter release frequency. A, SNAP-25 immunofluorescence images of wt bovine chromaffin cells and cells overexpressing SNAP-25 wt or the R198Q, R198E, K201Q, or K201E SNAP-25 mutant. Scale bar, $10 \mu \mathrm{m}$. B, Averaged fluorescence intensity after background subtraction (AU) of native bovine chromaffin cells and cells overexpressing SNAP- 25 wt $(8265 \pm 456, n=6)$ or R1980 $(8178 \pm 489, n=6)$, R198E (8424 \pm 347 , $n=6), \mathrm{K} 201 \mathrm{Q}(8505 \pm 390, n=6)$, or K201E $(8081 \pm 328, n=6)$ mutants. C, Amperometric recording of catecholamine release from bovine chromaffin cells overexpressing SNAP-25 wt or R198Q, R198E, K201Q, or K201E mutants, stimulated by $100 \mathrm{~mm} \mathrm{KCl}$. $D$, Averaged release frequency (events per minutes) in cells overexpressing SNAP-25 wt $(n=16)$, or R198Q $(n=15)$, R198E $(n=15)$, K201Q ( $n=18)$, K201E $(n=16)$ mutants in $100 \mathrm{~mm} \mathrm{KCl} .{ }^{*} p<0.05$ (one-way ANOVA test). 
A
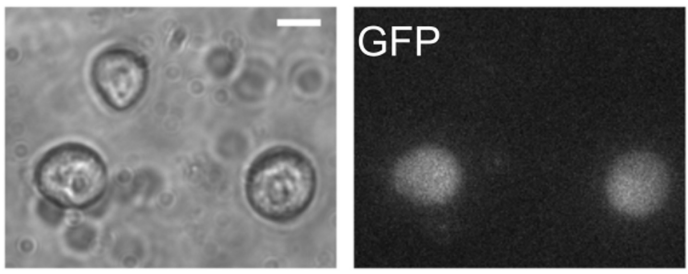

B
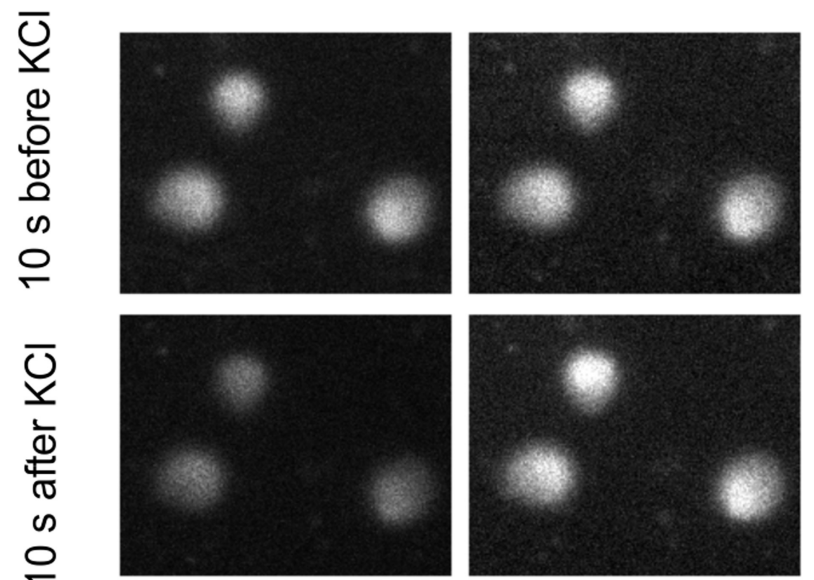

C

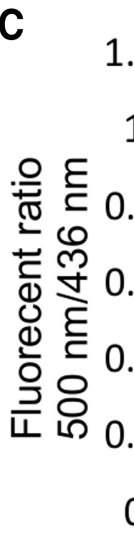

D

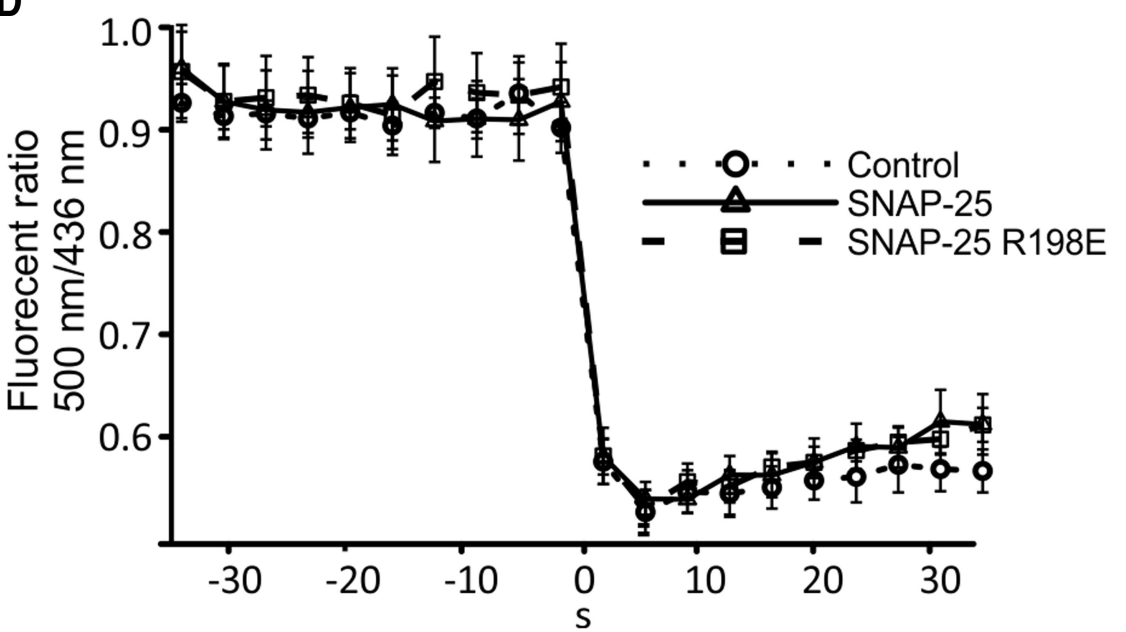

Figure 2. Overexpression of SNAP-25 wt or SNAP-25 R198E does not change the intracellular free $\mathrm{Ca}^{2+}$ concentration before or after KCl stimulation. A, Bright-field (left) and GFP fluorescence images (right) of bovine chromaffin cells overexpressing SNAP-25 R198E after loading with fura-red. Scale bar, $10 \mu \mathrm{m} . \boldsymbol{B}$, Fura-red fluorescence images with 436 or $500 \mathrm{~nm}$ excitation acquired $10 \mathrm{~s}$ before and $10 \mathrm{~s}$ after onset of stimulation. $C$, Fluorescence ratio of wt chromaffin cells, cells overexpressing SNAP- $25 \mathrm{wt}$, or cells overexpressing SNAP-25 R198E before ( -34 to $-5.4 \mathrm{~s}$ ) and after (5.4 to $34 \mathrm{~s}$ ) KCl stimulation, with the excitation wavelength of $500 \mathrm{~nm}$ over $436 \mathrm{~nm}$. D. Average time courses of fluorescence ratio of wt chromaffin cells and cells overexpressing SNAP-25 or SNAP-25 R198E before and after high KCl stimulation. Averages in $\boldsymbol{C}$ and $\boldsymbol{D}$ are from eight cells per group. row fusion pore stage (Albillos et al., 1997). The foot duration represents the time interval from the initial fusion pore opening to rapid expansion of the fusion pore and the foot amplitude indicates the average flux of transmitter through the narrow fusion pore during this time (Gong et al., 2007). When the positively charged K201 or R198 is mutated to a negatively charged glutamic acid (E), the foot duration was $\sim 40-50 \%$ longer (R198E, $14.1 \pm 1.4 \mathrm{~ms}$; K201E, $13.5 \pm 1.3 \mathrm{~ms})$ than that of SNAP-25 wt $(9.4 \pm 1.1 \mathrm{~ms})$ (Fig. $3 E)$. However, the foot durations of neutral amino acid mutants (R198Q, $10.6 \pm$ $1.3 \mathrm{~ms}$ and K201Q $8.2 \pm 0.8 \mathrm{~ms}$ ) were similar to that of SNAP-25 wt. For the foot amplitude (Fig. 3F), only the SNAP-25 R198 mutants show a decrease by 25\% (R198Q, $4.0 \pm 0.3$ pA; R198E, $4.2 \pm 0.2$ pA) compared with SNAP-25 wt (5.3 \pm $0.5 \mathrm{pA}$ ). Expression of SNAP-25 K201 mutants did not change the foot amplitude (K201Q, $5.0 \pm 0.4$ pA; K201E, $5.4 \pm$ $0.6 \mathrm{pA}$ ) compared with SNAP-25 wt.

Although SNAP-25 knock-out mice are available, the small vesicle capacitance and short fusion pore duration in mouse cells make analysis of fusion pore properties unreliable. The SNAP-25 mutants were therefore expressed in bovine cells that are not devoid of SNAP-25 wt. However, the overexpression levels are $\sim 7$ fold higher than those of endogenous SNAP-25 (Fig. 1A,B). If a mutant would be nonfunctional and observed fusion events were only generated by SNARE complexes incorporating only SNAP$25 \mathrm{wt}$, these fusion events would have properties indistinguishable from those observed when only SNAP-25 wt is expressed. In contrast, constructs that reduce the rate of fusion events produce also modified fusion pore properties, indicating that they do participate in the fusion mechanism. If nonfunctional mutants would affect fusion via nonspecific interactions such as overcrowding, cells overexpressing SNAP-25 wt should show changes compared with cells expressing only endogenous SNAP-25, which is not the case (Sørensen et al., 2003b; Fang et al., 2008), indicating that SNAP-25 overexpression does not affect fusion via nonspecific interactions.

Fusion pore conductance determined by cell-attached capacitance measurement

The reduced foot amplitude indicates reduced flux of transmitter through fusion pores in SNAP-25 R198Q and R198E mutants, which may reflect a change in 
structural features of the fusion pore. To test this hypothesis, we determined fusion pore conductance directly by cellattached capacitance measurements (Debus and Lindau, 2000) in which a fusion event is indicated by a capacitance step. Most fusion events detected by cellattached capacitance measurement were full fusion events and only few transient (kiss and run) fusion events were observed $(10,2,5,7$, and 5 events for SNAP25 wt, R198Q, R198E, K201Q, and K201E mutants, respectively) consistent with previous results from wt chromaffin cells (Albillos et al., 1997). An increase in frequency of kiss and run events appears to be induced by a high $\mathrm{Ca}^{2+}$ concentration in the pipette solution (Alés et al., 1999).

In bovine chromaffin cells, the fusion pore opening typically manifests itself as a transient increase in the real part $\left(R_{\mathrm{e}}\right)$ of the patch admittance on the time scale of 5-400 ms, and a time-resolved (noninstantaneous) increase in the imaginary part $\left(I_{\mathrm{m}}\right)$. From these traces, the time course of fusion pore conductance $\left(G_{\mathrm{p}}\right)$ and capacitance $\left(C_{\mathrm{v}}\right)$ was calculated (Fig. $4 A$ ). Three different types of fusion pore expansion dynamics were observed. In type I events, the imaginary trace and $G_{\mathrm{p}}$ increased continuously, indicating gradual expansion of the fusion pore, which was the dominant type of fusion pore expansion in wt cells. In type II and type III mode, $G_{\mathrm{p}}$ either stayed at a plateau level for $>10 \mathrm{~ms}$ (type II) or transiently decreased by $>50 \%$ from a previous conductance level (type III), which indicated that fusion pores stayed longer at a metastable state, during which time the fusion pore could shrink in diameter or elongate, both of which would transiently decrease fusion pore conductance. The initial $G_{\mathrm{p}}$ was taken at a time point where the $C_{\mathrm{v}}$ trace reached the full vesicle capacitance within $10 \%$ to account for the time resolution of the admittance measurement. The lifetime of the fusion pore (duration) was taken as the time between its initial opening and the time where the slope of $G_{p}$ increased sharply, indicating rapid fusion pore expansion (Fang et al., 2008).

The average capacitance step size (Fig. 4B) obtained from cells expressing SNAP-25 R198Q (2.72 $\pm 0.14 \mathrm{fF}), \mathrm{R} 198 \mathrm{E}$ $(2.66 \pm 0.16 \mathrm{fF}), \mathrm{K} 201 \mathrm{Q}(2.87 \pm 0.12 \mathrm{fF})$, or K201E ( $2.85 \pm 0.17$ fF) mutants was not significantly different from cells expressing SNAP-25 wt ( $2.95 \pm 0.15 \mathrm{fF})$, indicating unchanged vesicle size. Because quantal size also showed no difference between the SNAP-25 R198 or K201 mutants and SNAP-25 wt (Fig. 3D), the catecholamine concentration inside the vesicles was unchanged. The reduced foot amplitude of R198 mutants is thus presumably due to reduced permeability of the initial fusion pore, indicating a change in fusion pore structure. As for ion channels, changes in
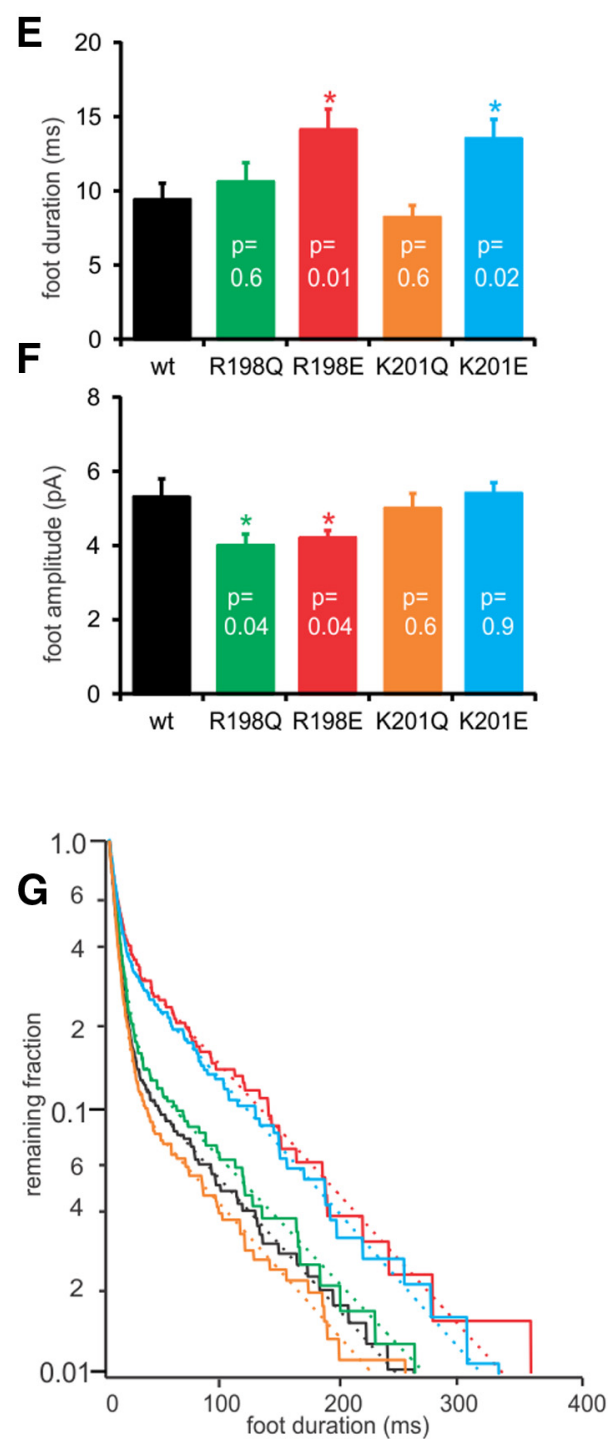

Figure 3. Positively charged amino acids at the SNAP-25 C terminus accelerate the transmitter release from single vesicles. $A, A$ single amperometric event from the SNAP-25 wt trace on expanded scale illustrating the parameters analyzed for amperometric (foot amplitude, foot duration, half-width, amplitude, and quantal size). $\boldsymbol{B}-\boldsymbol{F}$, Statistical analysis of quantal size $(\boldsymbol{B})$, spike half-width $(\boldsymbol{C})$, spike amplitude $(\boldsymbol{D})$, foot duration $(\boldsymbol{E})$, and foot amplitude $(\boldsymbol{F})$ obtained from cells overexpressing SNAP-25 wt $(n=$ 16 cells, 904 events) or R198Q ( $n=15$ cells, 595 events), R198E ( $n=15$ cells, 331 events), K201Q ( $n=18$ cells, 1038 events), or mutants R198Q (green, $n=244$ events), R198E (red, $n=133$ events), K201Q (orange, $n=467$ events), and K201E (blue, $n=193$ events). The dotted lines show fits of the decay with double exponential fit. ${ }^{*} p<0.05$ (one-way ANOVA test).

the structure of the fusion pore should be reflected in changes of its conductance. Consistent with the smaller foot amplitude observed with SNAP-25 R198Q and R198E mutants, the initial $G_{\mathrm{p}}$ (Fig. 4C) of SNAP-25 R198Q (224 \pm 16 pS) and R198E mutants $(215 \pm 29 \mathrm{pS})$ is $\sim 30 \%$ smaller than that of SNAP-25 wt (331 \pm $30 \mathrm{pS}$ ). However, the fusion pores observed with K201 mutants had an initial $G_{\mathrm{p}}$ (K201Q: $312 \pm 38$ pS; K201E $297 \pm 42 \mathrm{pS}$ ) similar to that of SNAP-25 wt fusion pores.

The fusion pore duration obtained from capacitance measurements on SNAP-25 R198E- $(22.5 \pm 2.4 \mathrm{~ms})$ or K201E ( $23.2 \pm 2.5 \mathrm{~ms}$ )-expressing cells was $\sim 75 \%$ longer than that of cells expressing SNAP-25 wt $(13.2 \pm 1.5 \mathrm{~ms})$, the SNAP-25 R198Q (11.5 $\pm 3.4 \mathrm{~ms})$, or K201Q (11.5 $\pm 3.4 \mathrm{~ms})$ mutants (Fig. $4 D$ ), which agrees well with the observed changes in foot duration obtained from amperometric recordings (Fig. 3E). From the 
A

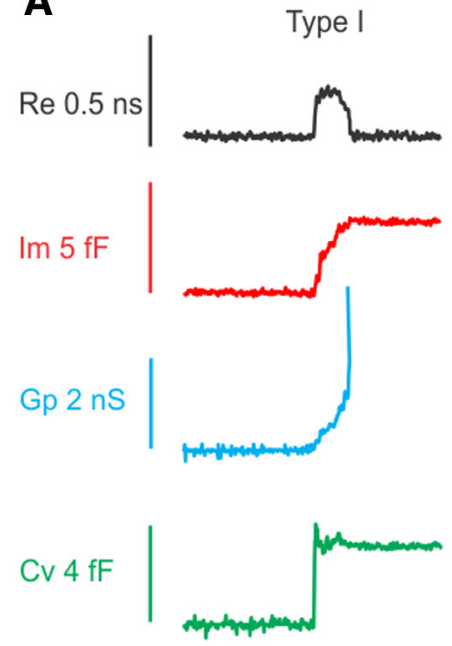

B

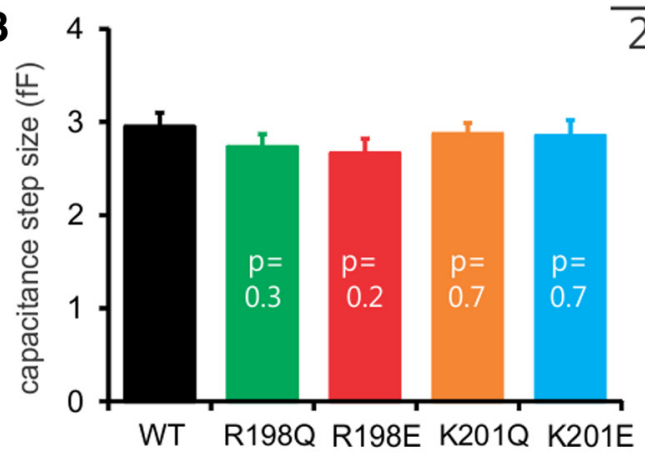

C

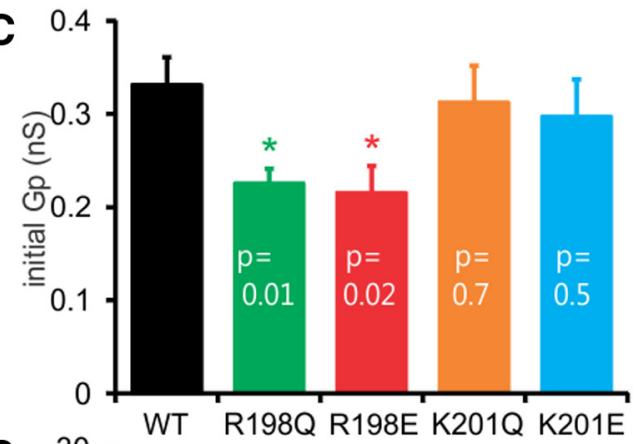

Type II
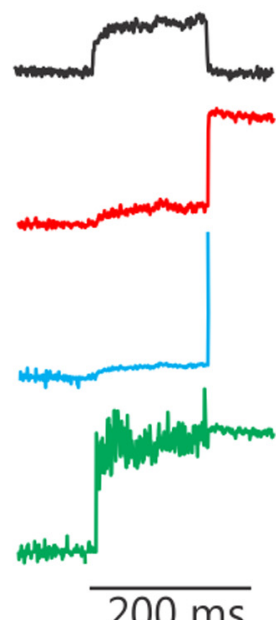

Type III

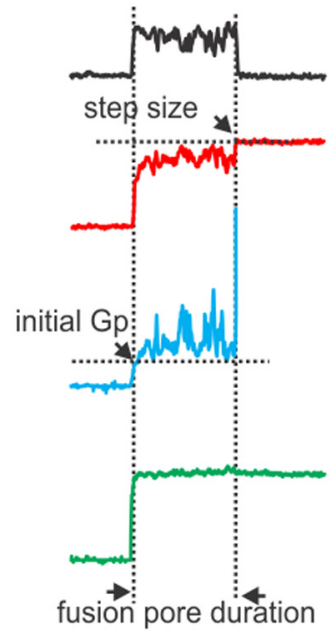

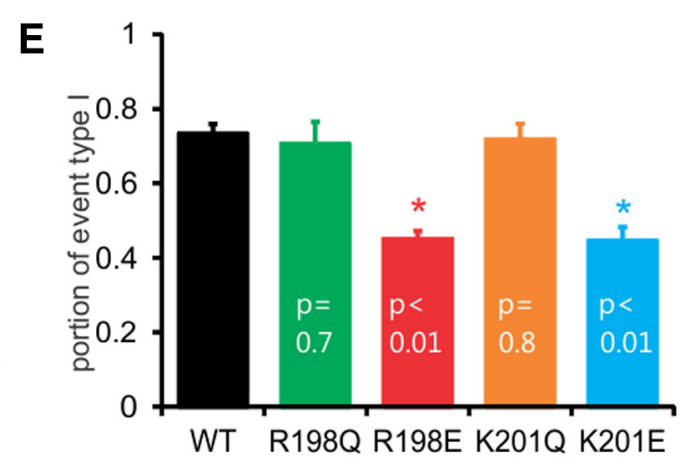

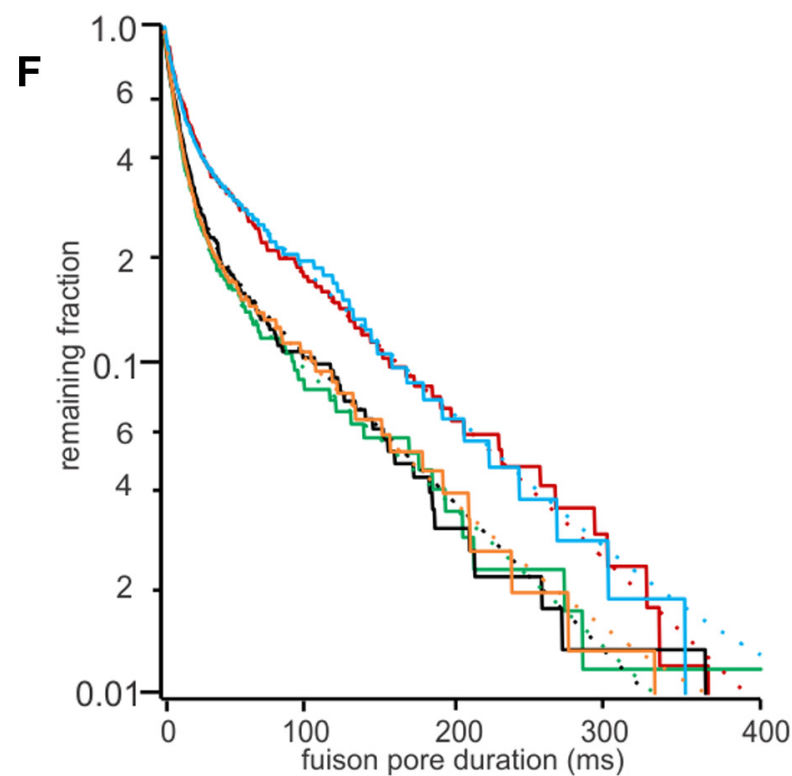

Figure 4. Fusion pore conductance analysis for SNAP-25 R198 mutants. $A$, Three types of fusion pore expansion modes. Real part ( $R_{\mathrm{e}}$ black) and imaginary part of admittance change $\left(I_{\mathrm{m}}\right.$, red), fusion pore conductance $\left(G_{p}\right.$, blue), and fusion pore capacitance $\left(C_{v}\right.$ green) are shown. Type I, Continuous expansion; type II, expansion with plateau (duration of the plateau is longer than $\left.10 \mathrm{~ms}\right)$; type III, expansion with flicker $(s)\left(G_{p}\right.$ decreases $\left.>50 \%\right)$. $\boldsymbol{B}-\boldsymbol{E}$, Statistical analysis of capacitance step size $(\boldsymbol{B})$, initial fusion pore conductance $(\boldsymbol{C})$, fusion pore duration (D), and portion of different types of fusion pore expansion modes (E) from cells overexpressing SNAP-25 wt $(n=22)$ or R198Q $(n=14), \operatorname{R} 198 \mathrm{E}(n=11), \mathrm{K} 201 \mathrm{Q}(n=15)$, or K201E ( $n=12)$ mutants. $\boldsymbol{F}$, Survival curves of fusion pore duration for SNAP-25 wt (black $n=232$ events) and SNAP-25 mutants R198Q (green, $n=176$ events), R198E (red, $n=172$ events), K201Q (orange, $n=155$ events), and K201E (blue, $n=$ 108 events). The dotted lines show double exponential fits of the decay. ${ }^{*} p<0.05$ (one-way ANOVA test). 
measured fusion pore duration, fusion pore survival curves were constructed (Fig. 4F) for SNAP-25 wt and the mutants, representing the cumulative fusion pore lifetime distributions. These curves are not single exponentials. Double exponential fits (Fig. $4 F$, dotted lines) reproduce the data well and the resulting fit parameters (see Table 2) show a marked increase in the slow component for the SNAP-25 R198E and K201E mutant. The lifetime distribution for prespike feet also shows a doubleexponential decay (Fig. 3F, Table 1) very similar to that of the fusion pore durations obtained by capacitance measurements. The fast component of the prespike feet was somewhat faster and the contribution of the slow component A-slow/(A-fast + A-slow) was smaller, which is due to the higher time resolution of the amperometric recording such that shorter lifetimes are included compared with the fusion pore durations from capacitance measurements. Approximately $20-25 \%$ of the amperometric foot signals had a duration between $2 \mathrm{~ms}$ and $4.5 \mathrm{~ms}$.

Of the three types of fusion pore opening (Fig. $4 A$ ), type I events have shorter duration than type II and III fusion pores that exhibit a plateau or flickers. For SNAP-25 wt, SNAP-25 R198Q, and $\mathrm{K} 201 \mathrm{Q}$ mutants, type I is the dominant fusion pore type $(\sim 70 \%$, Fig. $4 E)$. However, for the SNAP-25 R198E and K201E mutants, more than half of events show delayed fusion pore expansion of type II or type III.

\section{Molecular dynamics simulations to identify the structural implications of R198 and K201 mutations}

To investigate the structural basis of the modified fusion pore properties, coarse grain (CG) molecular dynamics (MD) simulations were performed. The structure of a wt SNARE complex (consisting of the fragments Syb2 25-93, Stx1A 188-259, SNAP-25 7-83 and SNAP-25 131-204) was taken from Sutton et al. (1998) (pdb file 1SFC). The transmembrane domains of Syb2 and Stx1A were not included because they are in two different membranes and are unable to interact with each other before the fusion pore is formed. The two C terminal residues of SNAP-25, Ser 205 and Gly 206, are missing in the crystal structure and were therefore added as a helical extension at the C terminus of SNAP25. The atomic structures were converted to CG particles, followed by solvation using the MARTINI force field. This operation may result in some unfavorable interactions of the CG particles, which were relaxed by a standard steepest descend energy minimization before the MD simulation was started. The CG model of the SNARE complex is shown in Figure 5A. Syb2 and Stx1A are the transmembrane proteins that will transfer the force generated by the SNARE complex to the vesicle and plasma membrane, respectively, when the fusion pore is formed. The force is thought to be produced by vectorial zippering of the SNARE domains toward the $\mathrm{C}$ terminus. Therefore, the distance between the backbone particles of the $\mathrm{C}$ terminal layer 8 residues of Syb2 (Leu 84) and the corresponding Stx1A residue (Ala 254) (Fig. $5 A, B$, layer 8 distance) was analyzed as a critical parameter that may determine fusion pore properties. Trajectories of this distance revealed transitions between two states termed loose and tight state, respectively (Fig. $5 C, D$ ).

From the trajectories of Figure $5 C$, a frequency distribution of the layer 8 distance in the wt SNARE complex was generated (Fig. $5 E$, solid line), which shows two peaks at $\sim 0.67 \mathrm{~nm}$ and $\sim 0.52$ $\mathrm{nm}$ and could be fitted with a sum of two Gaussians (Fig. 5E, dotted line). The two components of the Gaussian fit are shown as dashed lines in Figure 5E. The mean peak positions and their SEs were determined from fitting the frequency distributions
Table 1. Prespike foot signal survival curve fit parameters obtained with double-exponential fits

\begin{tabular}{llll}
\hline Cell group & $\tau$-fast, $\mathrm{ms}$ & $\tau$-slow, ms & A-slow/(A-fast + A-slow) \\
\hline SNAP-25 wt & $6.60 \pm 0.02$ & $87.8 \pm 0.3$ & $0.15 \pm 0.01$ \\
SNAP-25 R1980 & $7.71 \pm 0.04$ & $92.0 \pm 0.7$ & $0.17 \pm 0.01$ \\
SNAP-25 R198E & $7.30 \pm 0.08$ & $88.7 \pm 0.4$ & $0.41 \pm 0.03$ \\
SNAP-25 K2010 & $6.76 \pm 0.02$ & $87.0 \pm 0.6$ & $0.12 \pm 0.01$ \\
SNAP-25 K201E & $7.02 \pm 0.05$ & $85.8 \pm 0.3$ & $0.37 \pm 0.02$ \\
\hline
\end{tabular}

from the eight individual simulations of Figure $5 C$ separately and averaging the best fit parameters (see Table 3 ).

The corresponding layer 8 distance distributions for the SNAP-25 mutants are compared with the wt distribution in Figure $5 F$. The two components of the fit are shown as dashed lines for the R198E mutant (red), which shows the largest change. The fit results for SNAP-25 wt and all mutants are given in Table 2. The fits revealed similar peak positions of the two states for the different mutants (Table 3).

The frequency histograms of Figure $5 F$ reflect the free energy landscapes shown in Figure 5G. For SNAP-25 wt and SNAP-25 K201Q mutant, the free energy differences $(\Delta G)$ between the tight and loose states are similar $\sim 0.69 \pm 0.33 \mathrm{k}_{\mathrm{B}} \mathrm{T}$ and $0.81 \pm$ $0.31 \mathrm{k}_{\mathrm{B}} \mathrm{T}$, respectively. However, for SNAP-25 K201E, R198Q, and R198E mutants, the $\Delta G$ between the tight and loose states increased to $1.28 \pm 0.34 \mathrm{k}_{\mathrm{B}} \mathrm{T}, 1.16 \pm 0.20 \mathrm{k}_{\mathrm{B}} \mathrm{T}$ and $1.80 \pm 0.25$ $\mathrm{k}_{\mathrm{B}} \mathrm{T}$ (Table 3). At least for the R198E mutant, which produces the largest reduction in fusion frequency (Fig. $1 C, D$ ), the increase of $\Delta G$ is highly significant.

\section{Discussion}

\section{Frequency of fusion events}

Fusion pore formation is thought to be induced by a force transfer generated by tight $\mathrm{C}$ terminal zippering of the SNARE domains. Here, we investigated the contribution of the positively charged residues R198 and K201 at the SNAP-25 C terminus. The frequency of fusion events is progressively reduced in cells expressing the R198Q, K201E, or R198E mutant. A reduction in the fusion rate was previously reported for K201E (Gil et al., 2002).

The fusion rate will be affected when the energy of an intermediate state in the fusion mechanism is perturbed. To investigate how the energy of $\mathrm{C}$ terminal zippering is affected by the R198 and K 201 mutations, we performed CG MD simulations of the coiled coil formed by the SNARE domains of SNAP-25, Syb2 and Stx1A. Although the time scale of the simulations is much shorter than the experimental time scale, the simulation trajectories allow the determination of the free energy landscape of $\mathrm{C}$ terminal zippering choosing the distance between the layer +8 residues of Syb2 and Stx1A as reaction coordinate. The simulations revealed spontaneous transitions between a loose and tight state with an energy difference $\Delta G$ of $\sim 0.7 \mathrm{k}_{\mathrm{B}} \mathrm{T}$ between them. These states may be considered substates of the C-terminally zippered SNARE domains. If the SNARE complex needs to be in the tight state to proceed to fusion pore opening, then this $\Delta G$ contributes to the activation energy and the fusion rates for the different mutants $k_{\text {mut }}$ are expected to relate to the fusion rate of wild-type SNAP- $25 k_{\mathrm{wt}}$ as follows:

$$
k_{m u t} \approx k_{w t} \cdot e^{-\frac{\Delta \Delta G}{R T}}
$$

where $\Delta \Delta G$ is the change in $\Delta G$ between the loose and tight state. Such a correspondence between fusion rates and $\Delta \Delta G$ values is indeed observed. 
A

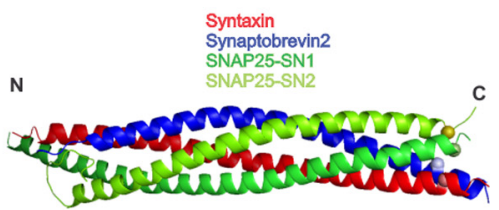

C
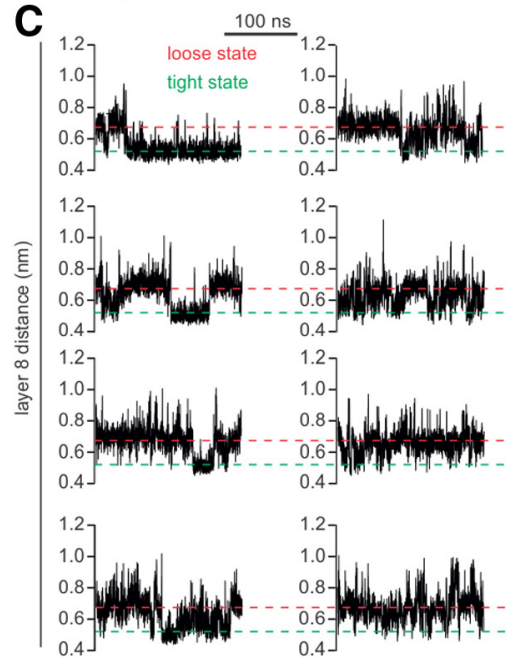

B

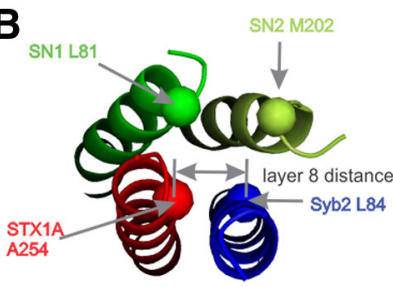

D1

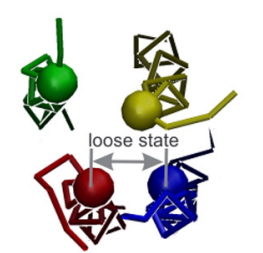

D2

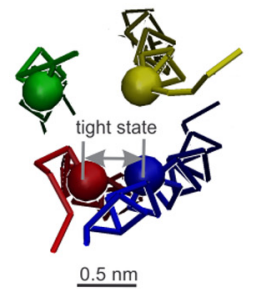

E
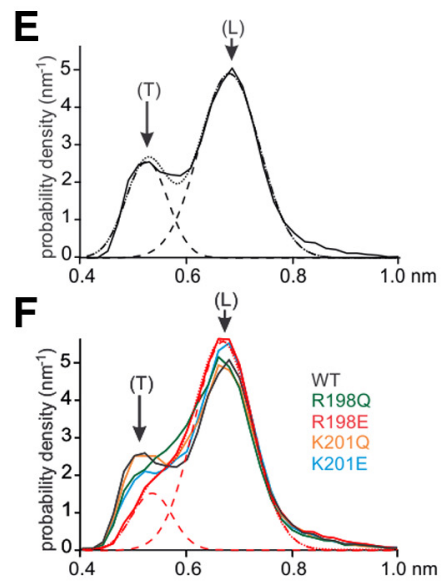

G

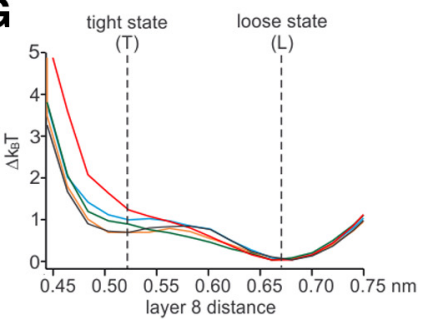

Figure 5. Positively charged amino acids at C terminus of SNAP-25 promote tight SNARE complex zippering. A, B, SNARE complex crystal structure with completed SNAP-25 C terminus indicating the measured distance between layer 8 Syb2 L84 and Stx1A A254 backbone particles. C, Eight individual simulation trajectories of distance between Syb2 L84 and Stx1A A254 of wt SNARE complex. $\boldsymbol{D}$, Representative structures of loose $\left(\boldsymbol{D}_{\mathbf{I}}\right)$ and tight $\left(\boldsymbol{D}_{\text {III }}\right)$ state. $\boldsymbol{E}$, Probability density of distance between Syb2 L84 and Stx1A A254 of wt SNARE complex (solid line) and fit with sum of two Gaussians (dotted line). Individual Gaussian components are shown as dashed lines. $\boldsymbol{F}$, Probability density distributions as in $\boldsymbol{E}$ for SNAP-25 mutants R1980 (green), R198E (red), K201Q (orange), and K201E (blue), including the Gaussian fit curves for R198E. G, Free-energy profiles of SNARE complex related to the distance between Syb2 L84 and Stx1A A254. The two vertical dashed lines indicate mean distance for the tight (T) and loose (L) states of the SNARE complex C terminus.

Table 2. Fusion pore survival curve fit parameters obtained with double-exponential fits

\begin{tabular}{llrl}
\hline Cell group & \multicolumn{1}{l}{$\tau$-fast, $\mathrm{ms}$} & \multicolumn{1}{c}{$\tau$-slow, ms } & A-slow/(A-fast + A-slow) \\
\hline SNAP-25 wt & $10.71 \pm 0.06$ & $88.1 \pm 0.5$ & $0.29 \pm 0.05$ \\
SNAP-25 R1980 & $10.32 \pm 0.08$ & $102.5 \pm 0.8$ & $0.25 \pm 0.03$ \\
SNAP-25 R198E & $12.03 \pm 0.20$ & $100.6 \pm 0.8$ & $0.46 \pm 0.06$ \\
SNAP-25 K2010 & $9.16 \pm 0.04$ & $91.0 \pm 0.4$ & $0.27 \pm 0.02$ \\
SNAP-25 K201E & $8.81 \pm 0.09$ & $92.7 \pm 0.4$ & $0.49 \pm 0.04$ \\
\hline
\end{tabular}

Compared with SNAP-25 wt, the fusion rate is reduced to $39 \%$ for the R198E mutant and to $48 \%$ for the K201E. According to Equation 1, such changes in kinetics would correspond to changes in activation energy by $\sim 0.95$ and $0.73 \mathrm{k}_{\mathrm{B}} \mathrm{T}$, respectively, in excellent agreement with the $\Delta \Delta G$ values of $1.1 \mathrm{k}_{\mathrm{B}} \mathrm{T}$ for $\mathrm{R} 198 \mathrm{E}$ and by $0.6 \mathrm{k}_{\mathrm{B}} \mathrm{T}$ for K201E obtained in the simulations (Table 3 ). For $\mathrm{R} 198 \mathrm{Q}$, the fusion rate is reduced to $70 \%$ of wt, corresponding to a change in activation energy by $\sim 0.35 \mathrm{k}_{\mathrm{B}} \mathrm{T}$, which is also in good agreement with the $\Delta \Delta G$ from the simulation results $(0.5$ $\mathrm{k}_{\mathrm{B}} \mathrm{T}$ ). For K201Q, which had unchanged fusion rates, the $\Delta \Delta G$ from the simulations was negligible $\left(0.1 \mathrm{k}_{\mathrm{B}} \mathrm{T}\right)$.

The SNAP-25 layer +7/+8 L78A/L81A/M202A triple mutant and, to a lesser degree, the layer +8 double mutant L81A/M202A slow down the rate of fusion events in response to a step increase in $\left[\mathrm{Ca}^{2+}\right]_{\mathrm{i}}$ (Sørensen et al., 2006). We therefore performed CG $\mathrm{MD}$ simulations also for these two constructs, which revealed a $\Delta \Delta G$ value for the $\mathrm{L} 78 \mathrm{~A} / \mathrm{L} 81 \mathrm{~A} / \mathrm{M} 202 \mathrm{~A}$ triple mutant of $\sim 1.2 \mathrm{k}_{\mathrm{B}} \mathrm{T}$, similar to that of R198E, and a smaller $\Delta \Delta G$ of $\sim 0.4 \mathrm{k}_{\mathrm{B}} \mathrm{T}$ for the L81A/M202A double mutant (Table 3). Notably, small corresponding changes were evident in the melting curves of the double (L81A/M202A) or the triple (L78A/L81A/M202A) SNAP-25 mutations (Sørensen et al., 2006).
Table 3. Statistical analysis of simulation results from $n=8$ independent simulations (errors are SEM)

\begin{tabular}{lllll}
\hline Cell group & $\begin{array}{l}\text { Distance tight } \\
\text { state }(\mathrm{nm})\end{array}$ & $\begin{array}{l}\text { Distance loose } \\
\text { state }(\mathrm{nm})\end{array}$ & $\Delta G\left(\mathrm{k}_{\mathrm{B}} \mathrm{T}\right)$ & $\Delta \Delta G\left(\mathrm{k}_{\mathrm{B}} \mathrm{T}\right)$ \\
\hline SNAP-25 wt & $0.521 \pm 0.007$ & $0.671 \pm 0.003$ & $0.69 \pm 0.33$ & 0 \\
SNAP-25 R1980 & $0.539 \pm 0.009$ & $0.662 \pm 0.005$ & $1.16 \pm 0.20$ & $0.47 \pm 0.38$ \\
& $p=0.14$ & $p=0.14$ & $p=0.25$ & \\
SNAP-25 R198E & $0.534 \pm 0.005$ & $0.665 \pm 0.004$ & $1.80 \pm 0.25$ & $1.11 \pm 0.41$ \\
& $p=0.16$ & $p=0.19$ & $p=0.019$ & \\
SNAP-25 K2010 & $0.526 \pm 0.009$ & $0.669 \pm 0.004$ & $0.81 \pm 0.31$ & $0.12 \pm 0.45$ \\
& $p=0.66$ & $p=0.66$ & $p=0.80$ & \\
SNAP-25 K201E & $0.533 \pm 0008$ & $0.671 \pm 0.003$ & $1.28 \pm 0.34$ & $0.59 \pm 0.47$ \\
& $p=0.24$ & $p=0.90$ & $p=0.24$ & \\
SNAP-25 L81A/M202A & $0.525 \pm 0.006$ & $0.673 \pm 0.005$ & $1.07 \pm 0.27$ & $0.38 \pm 0.43$ \\
& $p=0.67$ & $p=0.74$ & $p=0.39$ & \\
SNAP-25 L78A/L81A/ & $0.536 \pm 0.009$ & $0.680 \pm 0.005$ & $1.88 \pm 0.30$ & $1.19 \pm 0.45$ \\
M202A & $p=0.21$ & $p=0.15$ & $p=0.018$ & \\
Syb2 L84A & $0.513 \pm 0.003$ & $0.665 \pm 0.004$ & $1.25 \pm 0.28$ & $0.56 \pm 0.43$ \\
& $p=0.14$ & $p=0.25$ & $p=0.22$ & \\
\hline
\end{tabular}

$\overline{\Delta G \text { is the difference in free energy between these positions. } \Delta \Delta G \text { are the differences }\left(\Delta G_{\text {mutant }}-\Delta G_{\text {wt }}\right) \cdot p \text {-values }}$ indicate significance levels.

A reduction in fusion rate similar to that of the SNAP-25 L81A/M202A was reported for the Syb2 layer +8 L84A mutant (Walter et al., 2010) and simulations revealed a $\Delta \Delta G$ value of 0.56 for this mutant (Table 3), similar to that of SNAP-25 L81A/ M202A. The changes in fusion rates for the different mutants studied here (Fig. 1C,D) and for the previously studied layer $+7 /+8$ mutations thus correspond extremely well with the $\Delta \Delta G$ values of the tight state compared with the loose state and the measured changes in SNARE complex stability, suggesting that a 
transition from the loose to the tight state is required for fusion pore formation.

\section{Early fusion pore conductance and dynamics}

The initial fusion pores formed by SNAP-25 R198Q and R198E have a $30 \%$ lower conductance than fusion pores formed by SNAP-25 wt (220 pS vs $330 \mathrm{pS}$ ) and a correspondingly smaller amperometric foot current amplitude. These changes suggest a narrower and/or longer fusion pore and are similar to those obtained with SNAP-25 $\Delta$, which lacks the $9 \mathrm{C}$ terminal residues including R198 (Fang et al., 2008).

The simulations revealed that the tight state (labeled $\mathrm{T}$ in Fig. $5 F, G)$ is associated with a local maximum in the probability distributions (Fig. $5 F$ ) and a corresponding well in the free energy landscapes (Fig. 5G) for the wt protein, K201Q, and K201E (black, brown, blue lines), but not in those for R198Q and R198E (green, red lines). This correspondence suggests that the transient stabilization of the tight state may be required to support fusion pores with average initial $G_{\mathrm{p}}$ of $\sim 330 \mathrm{pS}$. In the absence of a local energy minimum for the tight state, the initial $G_{\mathrm{p}}$ is smaller, suggesting a change in structural features of the fusion pore.

The negatively charged amino acid in the SNARE complex structure closest to SNAP-25 R198 is SNAP-25 E75 with a median distance between the charged particles of R198 and E75 of $\sim 0.5$ $\mathrm{nm}$ in the CG MD simulations (data not shown). For the R198E mutant, the distance between the charged particles of E198 and E75 increased to $\sim 0.9 \mathrm{~nm}$ (data not shown). These results suggest that the stabilization of the tight state and the $330 \mathrm{pS}$ fusion pore conductance depend on electrostatic interaction between the charged side chains of R198 and E75.

Early fusion pores may fluctuate, producing flickering amperometric foot currents in recordings from mast cells (Alvarez de Toledo et al., 1993) and chromaffin cells (Zhou et al., 1996), which reflect fluctuations in transmitter release due to fluctuations in fusion pore conductance (Albillos et al., 1997; Gong et al., 2007). The fusion pore conductance measurements showed three types of fusion pore expansion modes (Fig. 4A), with rapid continuous expansion (type I), delayed expansion via a conductance plateau (type II), or conductance flickers (type III).

Fusion pores formed by SNAP-25 wt, R198Q, or K201Q showed similar dynamics, dominated by short duration and continuous expansion (type I). In contrast, the R198E or K201E mutants show more delayed fusion pore expansions (types II and III). Analysis of fusion pore duration revealed at least two kinetic components. For R198E and K201E, the slow component was markedly increased (Fig. 4F, Table 2) and the simulations revealed the largest $\Delta G$ values for the tight state (Table 2), suggesting that the increased energy of the tight state may prevent rapid and continuous fusion pore expansion.

In vitro experiments indicated that one SNARE complex may suffice for fusion pore formation, but several SNARE complexes appear to be needed for efficient fusion pore expansion (van den Bogaart et al., 2010; Shi et al., 2012). In addition, rapid release in chromaffin cells appears to require at least three SNARE complexes (Mohrmann et al., 2010) and it has been suggested that increased numbers of SNARE complexes produce more rapid fusion pore expansions (Südhof, 2013; Zhao et al., 2013). It is thus possible that the delayed fusion pore expansions of type II and III observed for the R198E and K201E mutants result from a change in the cooperativity of multiple SNARE complexes.

\section{Expanded fusion pore}

The onset of the amperometric spike indicates explosive dilation of the fusion pore to a large size with a conductance $>3 \mathrm{nS}$. Release through an expanded fusion pore may depend on the orifice of the expanded fusion pore (Amatore et al., 1999), the dissociation of transmitter from the intravesicular matrix (Wightman et al., 2002), slow diffusion within the intravesicular matrix (Amatore et al., 1999), and mechanical squeezing that appears to involve actin and myosin II (Berberian et al., 2009; Miklavc et al., 2012; Chiang et al., 2014). In chromaffin cells expressing SNAP-25 $\Delta 9$, the amplitude of amperometric spikes is reduced, whereas their half-width is increased, indicating slower release through the expanded fusion pore (Fang et al., 2008). This change presumably reflects a smaller orifice of the expanded fusion pore or reduced mechanical compression. Here, we show that release during the amperometric spike is slowed down in cells expressing the R198E, R198Q, or K210E mutant of SNAP25, consistent with a previous report for K201E (Gil et al., 2002). The increase in amperometric spike half-width (Fig. $3 C$ ) thus correlates with the decrease in release frequency for the different mutations (Fig. $1 D$ ) and with the increase in $\Delta G$ of the tightly zippered state (Fig. 5G, Table 2). The increase in $\Delta G$ therefore produces an increase in activation energy for fusion and also appears to limit fusion pore expansion.

In the final postfusion state, the SNARE complex acquires helical extension throughout the transmembrane domains (Stein et al., 2009). The destabilization of the tight state may affect this postfusion structure and thereby the orifice of the expanded fusion pore. Currently, the arrangements of SNARE complexes in early and expanded fusion pores are unknown. Additional insight could be obtained from structural studies of SNARE complexes carrying mutations that show defined changes in fusion pore properties like those described here.

\section{References}

Albillos A, Dernick G, Horstmann H, Almers W, Alvarez de Toledo G, Lindau M (1997) The exocytotic event in chromaffin cells revealed by patch amperometry. Nature 389:509-512. CrossRef Medline

Alés E, Tabares L, Poyato JM, Valero V, Lindau M, Alvarez de Toledo G (1999) High calcium concentrations shift the mode of exocytosis to the kiss-and-run mechanism. Nat Cell Biol 1:40-44. CrossRef Medline

Alvarez de Toledo G, Fernández-Chacón R, Fernández JM (1993) Release of secretory products during transient vesicle fusion. Nature 363:554-558. CrossRef Medline

Amatore C, Bouret Y, Midrier L (1999) Time-resolved dynamics of the vesicle membrane during individual exocytotic secretion events, as extracted from amperometric monitoring of adrenaline exocytosis from chromaffin cells. Chemistry 5:2151-2162.

Ashery U, Betz A, Xu T, Brose N, Rettig J (1999) An efficient method for infection of adrenal chromaffin cells using the Semliki Forest virus gene expression system. Eur J Cell Biol 78:525-532. CrossRef Medline

Berberian K, Torres AJ, Fang Q, Kisler K, Lindau M (2009) F-actin and myosin II accelerate catecholamine release from chromaffin granules. J Neurosci 29:863-870. CrossRef Medline

Breckenridge LJ, Almers W (1987) Currents through the fusion pore that forms during exocytosis of a secretory vesicle. Nature 328:814-817. CrossRef Medline

Calejo AI, Jorgačevski J, Silva VS, Stenovec M, Kreft M, Gonçalves PP, Zorec R (2012) Aluminium-induced changes of fusion pore properties attenuate prolactin secretion in rat pituitary lactotrophs. Neuroscience 201: 57-66. CrossRef Medline

Chiang HC, Shin W, Zhao WD, Hamid E, Sheng J, Baydyuk M, Wen PJ, Jin A, Momboisse F, Wu LG (2014) Post-fusion structural changes and their roles in exocytosis and endocytosis of dense-core vesicles. Nat Commun 5:3356. CrossRef Medline

Chow RH, von Rüden L, Neher E (1992) Delay in vesicle fusion revealed by 
electrochemical monitoring of single secretory events in adrenal chromaffin cells. Nature 356:60-63. CrossRef Medline

Condliffe SB, Corradini I, Pozzi D, Verderio C, Matteoli M (2010) Endogenous SNAP-25 regulates native voltage-gated calcium channels in glutamatergic neurons. J Biol Chem 285:24968-24976. CrossRef Medline

Debus K, Lindau M (2000) Resolution of patch capacitance recordings and of fusion pore conductances in small vesicles. Biophys J 78:2983-2997. CrossRef Medline

DeLano WL (2002) The PyMOL Molecular Graphics System. San Carolos, CA: DeLano Scientific. http://www.pymol.org.

Fang Q, Berberian K, Gong LW, Hafez I, Sørensen JB, Lindau M (2008) The role of the $\mathrm{C}$ terminus of the SNARE protein SNAP-25 in fusion pore opening and a model for fusion pore mechanics. Proc Natl Acad Sci U S A 105:15388-15392. CrossRef Medline

Fernández-Chacón R, Königstorfer A, Gerber SH, García J, Matos MF, Stevens CF, Brose N, Rizo J, Rosenmund C, Südhof TC (2001) Synaptotagmin I functions as a calcium regulator of release probability. Nature 410: 41-49. CrossRef Medline

Flašker A, Jorgačevski J, Calejo AI, Kreft M, Zorec R (2013) Vesicle size determines unitary exocytic properties and their sensitivity to sphingosine. Mol Cell Endocrinol 376:136-147. CrossRef Medline

Gao Y, Zorman S, Gundersen G, Xi Z, Ma L, Sirinakis G, Rothman JE, Zhang Y (2012) Single reconstituted neuronal SNARE complexes zipper in three distinct stages. Science 337:1340-1343. CrossRef Medline

Gil A, Gutiérrez LM, Carrasco-Serrano C, Alonso MT, Viniegra S, Criado M (2002) Modifications in the $\mathrm{C}$ terminus of the synaptosome-associated protein of $25 \mathrm{kDa}$ (SNAP-25) and in the complementary region of synaptobrevin affect the final steps of exocytosis. J Biol Chem 277:9904-9910. CrossRef Medline

Gong LW, de Toledo GA, Lindau M (2007) Exocytotic catecholamine release is not associated with cation flux through channels in the vesicle membrane but $\mathrm{Na}^{+}$influx through the fusion pore. Nat Cell Biol 9:915922. CrossRef Medline

Han X, Jackson MB (2005) Electrostatic interactions between the syntaxin membrane anchor and neurotransmitter passing through the fusion pore. Biophys J 88:L20-22. CrossRef Medline

Humphrey W, Dalke A, Schulten K (1996) VMD: visual molecular dynamics. J Mol Graph 14:33-38, 27-28. CrossRef Medline

Klyachko VA, Jackson MB (2002) Capacitance steps and fusion pores of small and large-dense-core vesicles in nerve terminals. Nature 418:89-92. CrossRef Medline

Li F, Pincet F, Perez E, Giraudo CG, Tareste D, Rothman JE (2011) Complexin activates and clamps SNAREpins by a common mechanism involving an intermediate energetic state. Nat Struct Mol Biol 18:941-946. CrossRef Medline

Maximov A, Tang J, Yang X, Pang ZP, Südhof TC (2009) Complexin controls the force transfer from SNARE complexes to membranes in fusion. Science 323:516-521. CrossRef Medline

Miklavc P, Hecht E, Hobi N, Wittekindt OH, Dietl P, Kranz C, Frick M (2012) Actin coating and compression of fused secretory vesicles are essential for surfactant secretion-a role for Rho, formins and myosin II. J Cell Sci 125:2765-2774. CrossRef Medline

Mohrmann R, de Wit H, Verhage M, Neher E, Sørensen JB (2010) Fast vesicle fusion in living cells requires at least three SNARE complexes. Science 330:502-505. CrossRef Medline

Monticelli L, Kandasamy SK, Periole X, Larson RG, Tieleman DP, Marrink SJ (2008) The MARTINI coarse-grained force field: extension to proteins. J Chem Theory Comput 4:819-834. CrossRef

Mosharov EV, Sulzer D (2005) Analysis of exocytotic events recorded by amperometry. Nat Methods 2:651-658. CrossRef Medline

Mundroff ML, Wightman RM (2002) Amperometry and cyclic voltammetry with carbon fiber microelectrodes at single cells. Curr Protoc Neurosci Chapter 6:Unit 6.14. CrossRef Medline

Parsons TD, Coorssen JR, Horstmann H, Almers W (1995) Docked gran- ules, the exocytic burst, and the need for ATP hydrolysis in endocrine cells. Neuron 15:1085-1096. CrossRef Medline

Shi L, Shen QT, Kiel A, Wang J, Wang HW, Melia TJ, Rothman JE, Pincet F (2012) SNARE proteins: one to fuse and three to keep the nascent fusion pore open. Science 335:1355-1359. CrossRef Medline

Sørensen JB (2009) Conflicting views on the membrane fusion machinery and the fusion pore. Annu Rev Cell Dev Biol 25:513-537. CrossRef Medline

Sørensen JB, Matti U, Wei SH, Nehring RB, Voets T, Ashery U, Binz T, Neher E, Rettig J (2002) The SNARE protein SNAP-25 is linked to fast calcium triggering of exocytosis. Proc Natl Acad Sci U S A 99:1627-1632. CrossRef Medline

Sørensen JB, Fernández-Chacón R, SüdhofTC, Neher E (2003a) Examining synaptotagmin 1 function in dense core vesicle exocytosis under direct control of Ca2 +. J Gen Physiol 122:265-276. CrossRef Medline

Sørensen JB, Nagy G, Varoqueaux F, Nehring RB, Brose N, Wilson MC, Neher E (2003b) Differential control of the releasable vesicle pools by SNAP-25 splice variants and SNAP-23. Cell 114:75-86. CrossRef Medline

Sørensen JB, Wiederhold K, Müller EM, Milosevic I, Nagy G, de Groot BL, Grubmuller H, Fasshauer D (2006) Sequential N- to C-terminal SNARE complex assembly drives priming and fusion of secretory vesicles. EMBO J 25:955-966. CrossRef Medline

Stein A, Weber G, Wahl MC, Jahn R (2009) Helical extension of the neuronal SNARE complex into the membrane. Nature 460:525-528. CrossRef Medline

Südhof TC (2013) Neurotransmitter release: the last millisecond in the life of a synaptic vesicle. Neuron 80:675-690. CrossRef Medline

Sutton RB, Fasshauer D, Jahn R, Brunger AT (1998) Crystal structure of a SNARE complex involved in synaptic exocytosis at $2.4 \AA$ resolution. Nature 395:347-353. CrossRef Medline

Tang J, Maximov A, Shin OH, Dai H, Rizo J, Südhof TC (2006) A complexin/synaptotagmin 1 switch controls fast synaptic vesicle exocytosis. Cell 126:1175-1187. CrossRef Medline

van den Bogaart G, Holt MG, Bunt G, Riedel D, Wouters FS, Jahn R (2010) One SNARE complex is sufficient for membrane fusion. Nat Struct Mol Biol 17:358-364. CrossRef Medline

Van Der Spoel D, Lindahl E, Hess B, Groenhof G, Mark AE, Berendsen HJ (2005) GROMACS: fast, flexible, and free. J Comput Chem 26:17011718. CrossRef Medline

Walter AM, Wiederhold K, Bruns D, Fasshauer D, Sørensen JB (2010) Synaptobrevin $\mathrm{N}$-terminally bound to syntaxin-SNAP-25 defines the primed vesicle state in regulated exocytosis. J Cell Biol 188:401-413. CrossRef Medline

Wang CT, Bai J, Chang PY, Chapman ER, Jackson MB (2006) Synaptotagmin$\mathrm{Ca} 2+$ triggers two sequential steps in regulated exocytosis in rat PC12 cells: fusion pore opening and fusion pore dilation. J Physiol 570:295-307. Medline

Wightman RM, Troyer KP, Mundorf ML, Catahan R (2002) The association of vesicular contents and its effects on release. Ann N Y Acad Sci 971:620-626. CrossRef Medline

Wiser O, Bennett MK, Atlas D (1996) Functional interaction of syntaxin and SNAP-25 with voltage-sensitive L- and N-type Ca2+ channels. EMBO J 15:4100-4110. Medline

Xu T, Binz T, Niemann H, Neher E (1998) Multiple kinetic components of exocytosis distinguished by neurotoxin sensitivity. Nat Neurosci 1:192200. CrossRef Medline

Zhao Y, Fang Q, Herbst AD, Berberian KN, Almers W, Lindau M (2013) Rapid structural change in synaptosomal-associated protein 25 (SNAP25) precedes the fusion of single vesicles with the plasma membrane in live chromaffin cells. Proc Natl Acad Sci U S A 110:14249_ 14254. CrossRef Medline

Zhou Z, Misler S, Chow RH (1996) Rapid fluctuations in transmitter release from single vesicles in bovine adrenal chromaffin cells. Biophys J 70: 1543-1552. CrossRef Medline 